\title{
Do recent data from the Seychelles Islands alter the conclusions of the NRC Report on the toxicological effects of methylmercury?
} Alan H Stern*1,2, Joseph L Jacobson ${ }^{3}$, Louise Ryan ${ }^{4,5}$ and Thomas A Burke 6

\begin{abstract}
Address: ${ }^{1}$ Bureau for Risk Analysis, Division of Science, Research, and Technology, New Jersey Department of Environmental Protection, 401 East State Street, 1st Floor, PO Box 409, Trenton, NJ, 08625, USA, ²Division of Environmental and Occupational Health, University of Medicine and Dentistry of New Jersey School of Public Health, 683 Hoes Lane West, Room 305, PO Box 9, Piscataway, NJ, 08854, USA, ${ }^{3}$ Department of Psychology, College of Science, Wayne State University, 235 Psychology Building, 71 West Warren, Detroit, MI, 48202, USA, ${ }^{4}$ Department of Biostatistics, Harvard School of Public Health, 655 Huntington Avenue, Boston, MA, 02115 USA, ${ }^{5}$ Dana-Farber Cancer Institute, 44 Binney Street, Mayer 219, Boston, MA 02115 USA and ' Department of Health Policy and Management, John Hopkins Bloomberg School of Public Health, 634 North Broadway, Room 484, Baltimore, MD, USA
\end{abstract}

Email: Alan H Stern* - Alan.Stern@dep.state.nj.us; Joseph L Jacobson - jjacobso@sun.science.wayne.edu; Louise Ryan - lryan@hsph.harvard.edu; Thomas A Burke - tburke@jhsph.edu

* Corresponding author

Published: 30 January 2004

Environmental Health: A Global Access Science Source 2004, 3:2

This article is available from: http://www.ehjournal.net/content/3/I/2

(C) 2004 Stern et al; licensee BioMed Central Ltd. This is an Open Access article: verbatim copying and redistribution of this article are permitted in all media for any purpose, provided this notice is preserved along with the article's original URL.
Received: 23 October 2003

Accepted: 30 January 2004

\begin{abstract}
In 2000, the National Research Council (NRC), an arm of the National Academy of Sciences, released a report entitled, "Toxicological Effects of Methylmercury." The overall conclusion of that report was that, at levels of exposure in some fish- and marine mammal-consuming communities (including those in the Faroe Islands and New Zealand), subtle but significant adverse effects on neuropsychological development were occurring as a result of in utero exposure. Since the release of that report, there has been continuing discussion of the public health relevance of current levels of exposure to Methylmercury. Much of this discussion has been linked to the release of the most recent longitudinal update of the Seychelles Island study. It has recently been posited that these findings supercede those of the NRC committee, and that based on the Seychelles findings, there is little or no risk of adverse neurodevelopmental effects at current levels of exposure. In this commentary, members of the NRC committee address the conclusions from the NRC report in light of the recent Seychelles data. We conclude that no evidence has emerged since the publication of the NRC report that alters the findings of that report.
\end{abstract}

\section{Introduction}

In 2000, the National Research Council (NRC), an arm of the National Academy of Sciences, released a report entitled, "Toxicological Effects of Methylmercury [1]" That NRC committee reviewed the existing literature on the health effects associated with exposure to methylmercury (MeHg), including relatively low-level exposure from current levels of fish consumption, and assessed the doseresponse relationship based on available epidemiological studies. The overall conclusion of that report was that, at levels of exposure in some fish- and marine mammal-con- suming communities (including those in the Faroe Islands [2] and New Zealand [3]), subtle but significant adverse effects on neuropsychological development were occurring as a result of in utero exposure. Based on those findings, the committee also concluded that "...the risk to that population [the women who consume large amounts of fish and seafood during pregnancy] is likely to be sufficient to result in an increase in the number of children who have to struggle to keep up in school". Since the release of that report, there has been continuing discussion of the public health relevance of current levels of 
exposure to MeHg. Much of this discussion has been linked to the release of the most recent longitudinal update of the Seychelles Island study by Gary Myers et al. [4], which reports no significant adverse neurological effects of in utero $\mathrm{MeHg}$ exposure at 9 years of age. It has been posited by the authors of that study in a letter to The Lancet [5], as well as in a commentary [6] and subsequent letter [7] by Constantine G. Lyketsos published in The Lancet, that these findings supercede those of the NRC committee, and that based on the Seychelles findings, there is little or no risk of adverse neurodevelopmental effects at current levels of exposure. As members of the NRC committee that wrote the 2000 report, we do not agree with this view. We, therefore, wish to address some of the key points raised by Drs. Myers and Lyketsos

\section{Discussion}

In his commentary, Lyketsos discounts the NRC report on the grounds that the Committee did not have access to the Seychelles 9-year follow-up data. However, at the time of its deliberation, the committee knew that this follow-up assessment was in progress and recognized that the consistent negative effects from the earlier stages of the Seychelles study made it highly unlikely that adverse effects would emerge in the 9-year follow-up. The Committee's conclusions, therefore, were based on an the consideration that the consistent adverse effects reported in the Faroe Islands and New Zealand studies would not be confirmed in this Seychelles cohort at any point in development. Thus, in our opinion the continued absence of negative effects in the most recent Seychelles data does not alter the overall interpretation of the data or the conclusions of the report.

In addition to assertions about how the new data from the Seychelles should alter the current view of the public health risk from methylmercury exposure, Lyketsos takes the position in that "the Seychelles study is methodologically the most advanced" study conducted to date. The basis for this assertion is unclear. From a research design perspective, the Seychelles and Faroes studies were very similar, and both were state-of-the-art. Both studies used continuous measures of exposure based on reliable biomarkers, statistical control for a broad range of potential confounders, and measurement of standard, wellrespected measures of neuropsychological function. Although the 9-year Seychelles follow-up assessed a larger number of developmental end points, adverse effects were seen in the Faroes and New Zealand studies in multiple domains of cognitive and neuromotor function.

The NRC report noted that there is a strong scientific consensus that blood lead concentrations in excess of $10 \mu \mathrm{g} /$ dL place a child at increased risk for poor developmental outcomes. Nevertheless, not all lead studies have found this association, and substantial variability exists in the magnitudes of the reported effects [8]. If two studies from this literature were chosen randomly, it is likely that the results would not be entirely concordant. A similar consensus is emerging regarding the effects of low-level PCB exposure on developmental outcomes despite some studies which failed to detect negative effects [9]. The uncertainties inherent in conducting human studies, which, for ethical reasons, must rely on statistical rather than experimental control for confounders, stem, in part, from unmeasured confounders and effect modifiers that may be idiosyncratic to the sample being studied, but can interfere with our ability to detect true effects and to replicate those found in other studies.

Thus, the failure to detect adverse effects in the Seychelles study could well be due to the substantial sample-to-sample variation expected when trying to identify relatively subtle effects on development in an inherently "noisy" system of complex, multi-determined neurobehavioral end points. The NRC report also emphasized that studyto-study comparisons are best made on the basis of the estimated value of parameters of interest, not simply on whether the studies yield "p $<.05$ ". In fact, the NRC analysis noted that comparing the studies with respect to their estimated benchmark doses and associated confidence limits noted much less discrepancy between them.

Myers et al., the authors of the Seychelles studies, argue in their letter to The Lancet [5] that hair mercury concentration is the only methylmercury exposure marker which has been correlated "against actual brain concentrations" [10] and that cord blood mercury has not. It should be noted that the correlation that Myers refers to is between mercury in maternal hair and infant brains. The same study also examined the correlation between mercury in infant blood and infant brains, and both sets of correlations were in the same range $(0.6-0.8$ vs. $0.4-0.8$, respectively). Since cord blood is the gestational surrogate of infant blood, the study cited by Myers et al. supports the conclusions reached in the NRC report; namely, that the use of either cord blood or maternal hair mercury is adequate for estimating the exposure dose. Since these metrics each provide information about different periods of development, use of both metrics will increase the likelihood of uncovering a true dose-response relationship. Both measures were, in fact, employed in the Faroes study and gave strikingly similar results although the cord blood measures generally yielded slightly stronger associations (in terms of p-values).

An essential point, which Myers et al. appear to have misconstrued, is that exposure misclassification (i.e., errors in matching the exposure-based biomarker of dose to the observed effect) generally makes it less likely to observe a 
true relationship and is highly unlikely to result in a spurious relationship. Both cord blood and maternal hair (and, in fact, all exposure measures) result in some degree of exposure misclassification. Thus, any exposure metric (including cord blood) which yields statistically valid relationships across a range of developmental endpoints provides useful information about the relationship between dose and response.

Another point which continues to be raised in the discussion of the applicability of the Faroes data to exposures in other communities is the notion of "bolus doses" [7]. It is important to point out that this notion is hypothetical and is supported by few data. Because the largest source of methylmercury exposure in the Faroese is consumption of whale meat that is relatively high in methylmercury concentration, it has been suggested that whale meat dinners might lead to isolated large spikes in methylmercury exposure during pregnancy. Grandjean has pointed out however, that in addition to whale dinners, stored (frozen and dried) portions of whale meat are also consumed in small amounts as snacks over extended periods of time [11]. Dietary assessments in both the Faroes and Seychelles studies were limited and the extent of "bolus" doses cannot be readily determined in either study. However, Grandjean et al. [12] report that the mercury concentration in the proximal $2 \mathrm{~cm}$ of pregnancy-period maternal hair in the Faroes study correlated with the concentration in full-duration pregnancy period hair with a coefficient of 0.93 . This is comparable to the correlation of 0.85-0.91 seen in a similar analysis in the Seychelles using hair segments of about $3 \mathrm{~cm}$ [7] and suggests that the influence of "bolus dose," if any, is comparable in the two studies. Grandjean et al. [12] further report that the individual children whose mother's hair showed the greatest variability in mercury concentration between segment and full length did not influence the outcome of the dose-response assessment, Lyketsos [7] appears to misunderstand the intent of such comparisons. These comparisons do not speak to the effect of variability in exposure per se on developmental outcomes, but speaks directly to the notion of bolus dose. The larger the bolus dose, the greater the variability that is expected between the mercury concentration in the segment and the full-length hair sample, which reflects average exposure. Thus, "bolus doses" in the Faroes cohort do not seem to be responsible for the observed effects of methylmercury on development.

Finally, issues have been raised as to the power of the various studies to detect an effect in developmental outcomes. Lyketsos [7] claims that the Seychelles study had power of $90 \%$ to detect neurodevelopmental effects of mercury toxicity, challenging the NRC report, which estimated that the Seychelles study had power of only $50 \%$ to detect several of the effects seen in the Faroes study. Given that the Faroe Islands and Seychelles studies had similar ranges of exposure, power considerations are driven primarily by sample size, so it stands to reason that the Seychelles study (just under 800 mother/infant pairs) will have less power than the Faroe study (over 1000 pairs). While it may well be true that the Seychelles study was designed with $90 \%$ power to detect a particular effect, it is also true that the study had only around $50 \%$ power to detect five of the eight effects seen in the Faroes (see Table 7-1 and Figure 7-2 of the NRC report).

\section{Conclusions}

In his letter, Lyketsos acknowledges that "it is beyond doubt" that mercury is neurotoxic and that there may be a need to warn pregnant women against eating certain seafood. [7] The key issue is the determination of the doses at which methylmercury is neurotoxic. The Reference Dose we recommended in the NRC report is derived from a benchmark dose of $58 \mu \mathrm{g} / \mathrm{l} \mathrm{MeHg}$ in blood. This corresponds to the exposure level that doubles the risk of adverse neurological development from $5 \%$ to $10 \%$ in the Faroes cohort. This is an important potential public health impact, which is preventable. In the interest of protecting public health, we believe it is better to err on the side of caution in the face of three well-designed studies, two of which are positive and one of which is negative. No evidence that has emerged since the publication of the NRC report changes our view on this issue. Once reasonable evidence of adverse effects has been provided, the issue is not whether methylmercury exposure from fish can pose a risk, but rather the dose (including an appropriate margin of safety) that is appropriate to provide prudent protection for the most vulnerable individuals in the population.

\section{List of abbreviations}

NRC - National Research Council

MeHg - methyl mercury

\section{Competing interests}

None declared.

\section{Authors' contributions}

All authors contributed to this commentary.

\section{References}

I. National Research Council: Toxicological Effects of Methylmercury Washington, D.C.: National Academy Press; 2000.

2. Grandjean $P$, Weihe $P$, White RF, Debes F, Araki S, Murata K, SØrensen N, Dahl D, Yokoyama K, JØrgensen PJ: Cognitive deficit in 7-year-old children with prenatal exposure to methylmercury. Neurotoxicol Teratol 1997, 19:4I7-428.

3. Crump KS, Kjellstrom T, Shipp AM, Silvers A, Stewart A: Influence of prenatal mercury exposure upon scholastic and psychological test performance: benchmark analysis of a New Zealand cohort. Risk Anal 1998, I 8:701-7I3. 
4. Myers G], Davidson PW, Cox C, Shamlaye CF, Palumbo D, Cernichiari E, Sloane-Reeves J, Wilding GE, Kost J, Huang LS, Clarkson TW: Prenatal methylmercury exposure from ocean fish consumption in the Seychelles child development study. Lancet 2003, 361:1686-1692.

5. Myers G], Cox C, Davidson PW, Huang L, Clarkson TW: Prenatal methylmercury exposure in the Seychelles. Lancet 2003, 362:665.

6. Lyketsos CG: Should pregnant women avoid eating fish? Lessons from the Seychelles. Lancet 2003, 36 I:1667.

7. Lyketsos CG: Prenatal methylmercury exposure in the Seychelles - Author's reply. Lancet 2003, 362:666-667.

8. Bellinger DC: Interpreting the literature on lead and child development: the neglected role of the "experimental system. Neurotoxicol Teratol 1995, 17:201-212.

9. Stewart PW, Reihman J, Lonky El, Darvill TJ, Pagano J: Cognitive development in preschool children prenatally exposed to PCBs and MeHg. Neurotoxicol Teratol 2003, 25: I I-22.

10. Cernichiari E, Brewer R, Myers G], Marsh DO, Lapham LW, Cox C, Shamlaye CF, Berlin M, Davidson PW, Clarkson TW: Monitoring methylmercury during pregnancy: maternal hair predicts fetal brain exposure. Neurotoxicology 1995, 16:705-710.

11. Workshop organized by Committee on Environmental and Natural Resources (CENR), Office of Science and Technology Policy (OSTP), The White House: Scientific Issues Relevant to Assessment of Health Effects from Exposure to Methylmercury, November 18_20, 1998.

12. Grandjean P, White RF, Weihe P, JØrgensen PJ: Neurotoxic risk caused by stable and variable exposure to methylmercury from seafood. Ambul Pediatr 2003, 3:18-23.

\section{Pre-publication history}

The pre-publication history for this paper can be accessed here:

http://www.biomedcentral.com/content/backmatter/ 1476-069X-3-2-b1.pdf

Publish with Bio Med Central and every scientist can read your work free of charge

"BioMed Central will be the most significant development for disseminating the results of biomedical research in our lifetime. "

Sir Paul Nurse, Cancer Research UK

Your research papers will be:

- available free of charge to the entire biomedical community

- peer reviewed and published immediately upon acceptance

- cited in PubMed and archived on PubMed Central

- yours - you keep the copyright 